\title{
Hypertension in Older Adults-Geriatrician Point of View
}

\section{Gunes ARIK1 and Burcu Balam YAVUZ1*}

1 Hacettepe University Faculty of Medicine, Department of Internal Medicine, Division of Geriatric Medicine, Ankara, Turkey

*Corresponding author: Burcu Balam YAVUZ, Hacettepe University Faculty of Medicine, Department of Internal Medicine, Division of Geriatric Medicine, Ankara, Turkey, Tel: +903123053071; E-mail: bbdogu@gmail.com

Rec date: Sep 09, 2014; Acc date: Sep 26, 2014; Pub date: Sep 28, 2014

Copyright: (c) 2014 Burcu Balam YAUVZ, This is an open-access article distributed under the terms of the Creative Commons Attribution License, which permits unrestricted use, distribution, and reproduction in any medium, provided the original author and source are credited.

\begin{abstract}
Prevalence of hypertension increases with advanced age; however, its awareness and control frequencies are still low. A variety of factors including physiological changes due to aging contribute to the increase in prevalence of hypertension in geriatric age group. Adverse outcomes of hypertension are much more frequent in older adults. Besides from end organ damage hypertension is linked to several geriatric syndromes namely dementia, falls, and quality of life. Diagnoses, treatment, follow up, and blood pressures goals differ in older adults and this geriatric age group needs special consideration while managing hypertension. Hypertension should be treated in older adults, but with caution and appropriate medication. The catch-phrase "Start low, go slow, but go!" should be applied for this age group. This review focuses on the special issues of hypertension in the older population.
\end{abstract}

Keywords Hypertension; Older adults; Geriatrics; Management; Diagnosis; Treatment

\section{Introduction}

Hypertension is the most important and most common modifiable risk factor for cardiovascular disease (CVD), also the leading cause of mortality among adults worldwide [1-3]. Prevalence of hypertension is high reaching up to $30-45 \%$ in the general population [4]. With aging the prevalence increases, affecting nearly $2 / 3$ of men and $3 / 4$ of women by age 75 years [5]. This is also same for Turkey, Patent Study revealed that the prevalence of hypertension in Turkey was $31.8 \%$ and increases to $75.1 \%$ in people aged 65 years and older [6]. Data from Framingham Heart Study identified that among men and women who were free of hypertension at age 55 years, their residual lifetime risk of developing hypertension is $93 \%$ and $91 \%$ at age 80 years, respectively [7]. Although the prevalence is high, awareness and control is extremely low [8-11]. National Health and Nutrition Examination Survey (NHANES) cycles from 1988 to 2008 were analyzed for the characteristics in hypertensive older patients ( $\geq 60$ years of age) compared with younger patients (18 to 39 years of age in 2007 to 2008 ), older patients were more likely to be aware ( $84 \%$ Vs $66 \%)$; more likely to be treated ( $80 \%$ Vs $50 \%$ ); less likely to have controlled blood pressure (64\% Vs $82 \%)$ [12]. Our national data showed similar frequencies. Awareness of hypertension in Turkish geriatric patients was found to be $88.9 \%$ and only $20.9 \%$ were under control [13]. According to a report from NHANES (1988- 2010) regarding US adults 80 years and older, the hypertension prevalence increased from $69.2 \%$ in $1988-1994$ to $76.5 \%$ in $2005-2010$. Awareness and treatment of hypertension also increased over time. Controlled hypertension among those treated, also increased from $30.4 \%$ in $1988-1994$ to $53.1 \%$ in 2005-2010 [11] Controlling hypertension reduces incidence of cardiovascular events and heart failure by $20 \%$ to $25 \%$, stroke by $30 \%$ to $40 \%$ and decreases mortality [14-18].

\section{Definition and Classification of Hypertension}

The conventional definition of hypertension is a systolic blood pressure (SBP) greater than $140 \mathrm{mmHg}$ or a diastolic blood pressure (DBP) greater than $90 \mathrm{mmHg}$ based upon three or more measurements at two or more visits [19,20]. According to 2014 ASH /ISH guidelines, for patients aged 80 years or older a SBP up to $150 \mathrm{mmHg}$ is regarded as acceptable [21]. The classification of hypertension is the same as suggested in 2003 seventh Joint National Committee and reaffirmed by ASH/ISH in $2014[19,21]$ For patients with a SBP between $120-139 \mathrm{mmHg}$, or a DBP between $80-89 \mathrm{mmHg}$, the term prehypertension is used. Stage 1 hypertension refers to a SBP between 140-159 $\mathrm{mm} \mathrm{Hg}$ or a DBP between 90-99 $\mathrm{mmHg}$. Stage 2 hypertension refers to a SBP $\geq 160 \mathrm{~mm} \mathrm{Hg}$ or a $\mathrm{DBP} \geq 100 \mathrm{~mm} \mathrm{Hg}$ (Table 1). In ESC/ESH 2007 and 2013 a different classification was accepted as seen in Table 2 [4,22].

\begin{tabular}{|l|l|}
\hline Category & Blood Pressure $(\mathbf{m m H g})$ \\
\hline Normal & $<120 / 80$ \\
\hline Prehypertension & $120-139 / 80-89$ \\
\hline Hypertension & $\geq 140 / 90$ \\
\hline Stage 1 & $140-159 / 90-99$ \\
\hline Stage 2 & $\geq 160 / 100$ \\
\hline
\end{tabular}

Table 1: Blood pressure classification. Note: Adapted from ASH/ISH and JNC-8 (20).

\begin{tabular}{|l|l|l|l|}
\hline Category & Systolic & & Diastolic \\
\hline Optimal & $<120$ & and & $<80$ \\
\hline Normal & $120-129$ & and/or & $80-84$ \\
\hline High normal & $130-139$ & and/or & $85-89$ \\
\hline Grade 1 hypertension & $140-159$ & and/or & $90-99$ \\
\hline
\end{tabular}




\begin{tabular}{|l|l|l|l|}
\hline Grade 2 hypertension & $160-179$ & and/or & $100-109$ \\
\hline Grade 3 hypertension & $\geq 180$ & and/or & $\geq 110$ \\
\hline Isolated systolic hypertension & $\geq 140$ & and & $<90$ \\
\hline
\end{tabular}

Table 2: Definitions and classification of office blood pressure levels $(\mathrm{mmHg})$. Note: Adapted from ESC/ESH (4).

\section{Pathophysiology of Hypertension and its Association with Age Related Changes}

Regardless of age, the cause of primary (essential) hypertension is not well known. A variety of factors have been implicated, including lifestyle factors such as obesity, being sedentary, consuming excess sodium. Some genetically determined factors are associated with hypertension such as increased activity of renin-angiotensinaldosterone system and sympathetic nervous system, and succeptibility to the effects of dietary salt on blood pressure [21]. Several other age related functional and structural changes could contribute to age associated increase in blood pressure. These changes include the stiffennig of arterial wall, decreased vascular compliance of great arteries, and increased systemic vascular resistance [23]. Endothelial dysfunction together with fibrosis impairs vasodilation and increases arterial stiffness. These changes lead to an increase of arterial wave reflections resulting in mismatch between aortic diameter and blood flow [24]. As a result, systolic blood pressure rises and due to diminished arterial compliance diastolic blood pressure falls, and pulse pressure increases in older patients $[6,8,25,26]$.

The regulation of vascular resistance is also affected by autonomic nervous system. Sympathetic nervous system activitiy increases with aging. Plasma norepinephrine levels have been demonstrated to be higher in older patients. Baroreceptor sensitivity is also decreased by aging. These changes contribute to age related increase in hypertension prevelance.

Another mechanism contributing to the elevation of blood pressure in older adults is increased salt sensitivity [27]. Age related decline in renal function leads to inability to excrete dietary sodium load. Sodium potasium adenosine triphosphatese pump activity also decreases, leading to an increased intracellular calcium concentration resulting in vasoconstriction and increased vascular resistance. Age related changes in renin- angiotensin-aldosterone system, low plasma renin levels and high aldosterone levels in older adults also contribute to salt sensitivity and elevated blood pressure [24].

\section{Special Issues Regarding Hypertension in Older Adults}

There are some issues that should be considered while diagnosing, treating, and monitoring hypertension in older adults. Isolated systolic hypertension, white coat hypertension, orthostatic hypotension, pseudohypertension, and resistant hypertension are common in older adults. As atherosclerosis increases with age, renovascular hypertension is also an important problem that should not be overlooked in geriatric patients.

Besides these special types of hypertension, there are some other issues that should be kept in mind while treating and following up a geriatric patient with hypertension. Excessive hypotensive response can occur after administrating antihypertensive drugs in older adults. Therefore, the catch-phrase "start low go slow" should be kept in mind while initiating medications. Besides, isometric exercise and other stressors may cause excessive hypertensive response in older adults.

Another important issue regarding hypertension and older adults is the adverse outcomes of hypertension. Most important adverse outcome is end organ damage, which is known to be more frequent in older adults than the younger ones. Risk of stroke, myocardial infarction, left ventricular hypertrophy, heart failure, atrial fibrillation, peripheral artery disease, chronic kidney disease, ophthalmologic complications of hypertension, and even sudden cardiac death increases in geriatric patients. Cardiovascular disease risk is 3-4 fold in hypertensive elderly than younger adults. Decline in quality of life is much more evident in older adults. Another important consequence of hypertension from a geriatrician point of view is cognitive decline. Middle age uncontrolled hypertension is a well-known risk factor for cognitive dysfunction in later life. Hypertension is a risk factor for mild cognitive impairment, vascular dementia, and Alzheimer's disease [19,28-35].

\section{Isolated systolic hypertension}

Isolated systolic hypertension (ISH) is defined as a $\mathrm{SBP} \geq 140 \mathrm{~mm}$ $\mathrm{Hg}$ with a $\mathrm{DBP}<90 \mathrm{~mm} \mathrm{Hg}[20,36]$. ISH accounts for $60 \%$ to $80 \%$ of hypertension in older adults, as age getting older, the prevalence of ISH increases [8,26,36-38]. SBP is the most important determinant of the cardiovascular risk in older adults. ISH is associated with a two- to fourfold increase in the risk of myocardial infarction, stroke, and death due to cardiovascular disease [39-41] In several clinical trials, the importance of treating ISH has been demonstrated. In the Systolic Hypertension in the Elderly Program (SHEP) trial, for example, including 4376 patient with a mean age of 72 , the baseline blood pressure was $170 / 77 \mathrm{~mm} \mathrm{Hg}$. The attained mean blood pressure was $143 / 68$ with chlorthalidone therapy. Despite the low attained DBP in the treatment group, the incidence of stroke was significantly lower [42] However, when DBP falls below $60 \mathrm{~mm} \mathrm{Hg}$, adverse cardiovascular events significantly increased in older patients [43]. Similarly in the INVEST trail, an increased risk of myocardial infarction was demonstrated at DBP below $70 \mathrm{mmHg}$ [44]. In the Roterdam study the risk of stroke increased at DBP below $65 \mathrm{mmHg}$ [45]. These worse outcomes in elderly patients could be attributed to inability to maintain perfusion of vital organs, such as heart and brain at low diastolic pressures. When treating ISH, a minimum DBP of 60 $\mathrm{mm} \mathrm{Hg}$ overall or perhaps $65 \mathrm{~mm} \mathrm{Hg}$ in elderly patients with known coronary artery disease is suggested, unless the symptoms of hypoperfusion occur at higher diastolic pressures.

\section{White coat hypertension}

White coat hypertension (WCH) or isolated office hypertension is defined as increased blood pressure at doctor's office while repeatedly normal at home $(19,21)$. This situation is common in geriatric patients. In a report, $72.1 \%$ of elderly patients having office blood pressure $\geq 140 / 90 \mathrm{~mm} \mathrm{Hg}$ diagnosed as $\mathrm{WCH}$ after ambulatory blood pressure monitoring (ABPM) [46]. WCH should be diagnosed to avoid overtreatment. ABPM should be considered to diagnose $\mathrm{WCH}$, daytime average ambulatory blood pressure should be $<135 / 85 \mathrm{~mm}$ $\mathrm{Hg}$ when office blood pressure is $\geq 140 / 90 \mathrm{~mm} \mathrm{Hg}$. As WCH does not cause morbidity and mortality and treatment of WCH has not shown any benefit in Syst-Eur study, it is important to detect WCH in order to avoid polypharmacy and inapproppriate drug use in older adults [47]. 


\section{Orthostatic hypotension}

Orthostatic hypotension $(\mathrm{OH})$ is defined as a sustained drop in SBP ( $>20 \mathrm{mmHg}$ ) or DBP (>10 $\mathrm{mm} \mathrm{Hg}$ ) within 3 minutes of standing up. $\mathrm{OH}$ is common in geriatric patients because of autonomic dysfunction, diminished baroreceptor sensitivity, and reduced heart rate responsiveness to postural changes. The prevalence is high reaching up to $20 \%$ in the elderly [48]. OH could be precipited by antihypertensive medications, especially alpha blockers and diuretics are more likely to cause $\mathrm{OH}$. Silent cerebral ischemia may ocur due to $\mathrm{OH}$. Syncope and falls result when $\mathrm{OH}$ impairs cerebral perfusion. $\mathrm{OH}$ is one of the most frequent causes of falls in older adults. $\mathrm{OH}$ also increases cardiovascular complications and mortality in geriatric patients $[49,50]$.

\section{Pseudohypertension}

Pseudohypertension is defined as a falsely increased SBP which is a result of markedly sclerotic arteries that do not collapse during inflation of the blood pressure cuff [50]. Because of age associated vascular changes and atherosclerosis, SBP may be falsely measured as elevated, which is called pseudohypertension. These patients may be wrongly diagnosed as having resistant hypertension. Therefore, in older patients with resistant hypertension but no end organ damage, pseudohypertension should be considered. Intraarterial blood pressure measurements may be required for correct diagnosis.

\section{Resistant hypertension}

Resistant hypertension is defined as failue to control blood pressure in patients taking full doses of appropriate three drugs including a diuretic [19]. It is a common problem in older adults mostly due to poor adherence to medications or usage of drugs that interfere with blood pressure control such as non-steroidal antiinflammatory drugs, steroids, and some antidepressants (eg. venlafaxine).

\section{Approach to Antihypertensive Treatment and Therapeutic Goals in Older Adults}

Randomised controlled trials have shown that treating hypertension in older adults show similar benefits as younger adults. Studies examining older hypertensive adults have demonstrated that stroke, cardiovascular events, and mortality rate decrease in the treatment arm [42,47,51-55]. Syst-Eur study also showed that cumulative rate of dementia decreased by $55 \%$ in the treatment arm [56]. HYVET study showed a reduction in fatal and nonfatal stroke, mortality, and cardiovascular mortality in the oldest old (aged 80 years and over) [15]. A meta-analysis showed that benefits of reducing blood pressure are similar between older and younger adults in terms of major cardiovascular events, and there was no difference between different antihypertensives [17]. Therefore, hypertension should be treated regardless of age even in the oldest old. However, it is important to remember that blood pressure goals should not be as strict as in younger patients.

The blood pressure goal is lower than $140 / 90 \mathrm{~mm} \mathrm{Hg}$ in patients younger then 60 years, and it is lower than $150 / 90 \mathrm{~mm} \mathrm{Hg}$ in patients aged 60 years and older [20]. In ESC/ESH guidelines the threshold for starting therapy is suggested as $\geq 160 / 90 \mathrm{~mm} \mathrm{Hg}$, blood pressure goal is suggested as SBP between 140-149 $\mathrm{mm} \mathrm{Hg}, \mathrm{DBP}<90 \mathrm{~mm} \mathrm{Hg}$ [4] However, in ASH/ISH guidelines, for patients aged 60 to 80 years without diabetes and chronic kidney disease, the threshold for starting treatment is given as $140 / 90 \mathrm{~mm} \mathrm{Hg}$, for patients older than 80 years the threshold for treatment is accepted as $150 / 90 \mathrm{~mm} \mathrm{Hg}$ [21]. The JNC 8 did not suggest lowering SBP below $140 \mathrm{mmHg}$, but, if lower systolic blood pressure levels are achived wihout adverse effects then pharmacologic treatment does not need to be adjusted [20]. In elderly diabetic and chronic kidney disease patients, the blood pressure goal is less than $140 / 90 \mathrm{~mm} \mathrm{Hg}[20,25,27]$. However, in ESC/ESH guidelines blood pressure goal for elderly patients with diabetes and renal disease is suggested as $<140 / 85 \mathrm{~mm} \mathrm{Hg}$. In the light of these three guidelines published within one year, it is appropriate to target $<150 / 90 \mathrm{~mm} \mathrm{Hg}$ as blood pressure goal in older adults. Diastolic blood pressure should not be reduced to levels below $60 \mathrm{~mm} \mathrm{Hg}$, or in patients with known coronary artery disease, below $65 \mathrm{~mm} \mathrm{Hg}$, and in patients over than 80 years of age below $70 \mathrm{mmHg}$ [43,57-60]. Systolic blood pressure should not be reduced below $140 \mathrm{mmHg}$ in the oldest old ( $>80$ years of age). In isolated systolic hypertension, SBP goal is less than $150 \mathrm{~mm}$ $\mathrm{Hg}$, but in tolarable patients, lowering SBP less than $140 \mathrm{~mm} \mathrm{Hg}$ could be tried. "J" curve in hypertension should always be kept in mind while treating older patients and blood pressure goals should be increased according to the guidelines.

All patients should undergo nonpharmacologic interventions, such as weight reduction, low sodium diet, moderate exercise, limiting alcohol comsumption and smoking cessation [19,60-62]. Life style modifications are the key point of controlling hypertension. As polypharmacy is a common problem in older adults usage of drugs that may cause an increase in blood pressure should be asked (eg; nonsteroidal anti-inflammatory drugs, decongestants, some antidepressants like venlafaxin, and glucocorticoids). In patients who fail to reach the blood pressure goals with lifestyle modifications, pharmacologic therapy should be initiated and nonpharmacologic therapies should be continued. The clinicians need to be cautious when treating hypertensive elderly patients, because most of older patients have concomitant comorbidities, they are at risk for polypharmacy, drug-drug interactions, and they are prone to drug side effects such as ortostatic hypotension and electrolyte abnormalities. In patients with stage 1 hypertension it is suggested to start with one drug, begin with low dose (approximately one half of those in younger patients) and increase slowly to a maximum tolerated dose. If blood pressure goal is not met with a single drug, consider to add new drugs from different classes. In patients with stage 2 hypertension or when baseline blood pressure is higher than $20 / 10 \mathrm{mmHg}$ of the targeted blood pressure, drug treatment should be considered after the diagnosis with 2 drug regimens but should be used cautiously in older adults due to risk of $\mathrm{OH}[4,21]$. Three drug regimens initiaing at the same time is not recommended in older adults; however, three or four drug combinations can be administered gradually during follow up. The blood pressure should be lowered gradually over a period of weeks to months in older patients $[4,15,63]$. Decreasing blood pressure may not be beneficial for frail elderly, so clinicians should be more cautious in case of frailty [64].

\section{Choice of Drug Therapy}

The most important aim in hypertension treatment in older adults is lowering blood pressure to the targeted levels compatible with age. The benefits of treating hypertension are seen regardless of the choice of drug. There are several classes of antihypertensive drugs. In older patients, medications that are most likely to produce side effects should be avoided, such as centrally acting alfa agonists (clonidine and a-methyldopa) and direct vasodilators (hydralazine and minoxidil). In 
single agent therapy, as a general statement, the level of blood pressure reduction achieved is more important than which drug is used $[4,17,65]$. Choice of drugs is influenced by age, ethnicity, and other coexisting comorbidities such as diabetes, coronary disease, heart failure, and chronic kidney disease. ACCF/AHA 2011 Expert Consensus Document on Hypertension in the Elderly recommends ACEI, ARB, CCB, diuretic, or combination as firstline therapy of hypertension in geriatric patients [60]. The AHA/ISH guidelines recommend thiazide diuretics or calcium channel blockers (CCB) as first line medications for patients older than 60 years. If second drug is needed, angiotensine conveting enzyme inhibitors or angiotensin receptor blockers (ACEI or $\mathrm{ARB}$ ) are recommended. If third drug is needed, a combination of $\mathrm{CCB}+\mathrm{ACEI}$ or $\mathrm{ARB}+$ thiazide diuretic is recommended [21]. The JNC8 recommends that, one of the three drug classes (thiazid diuretic, CCB, ACEI /ARB) could be used as initial therapy in nonblack general elderly population including diabetics. In black elderly patients a thiazide diuretic or CCB is suggested as initial therapy including the diabetics [20]. ESH/ESC suggest that, initial therapy should consist either a CCB or a thiazide diuretic and combination therapy can consist any two drugs from thiazid diuretic, CCB or ACEI /ARB [4]. $\beta$-blockers are not recommended as initial treatment, in the absence of compelling indications (previous myocardial infarction, angina pectoris, heart failure, or aortic aneurysm. In LIFE study use of a $\beta$-blocker resulted in worse outcomes than use of an ARB [66]. $\alpha$-blockers are not recommended as initial therapy. In one study an a-blocker resulted in worse outcomes then a diuretic as initial therapy [67]. Besides, $\alpha$-blockers are less preferred in the elderly because of their side effects such as $\mathrm{OH}$ and increased risk for falls, but they could be useful in treating resistant hypertension in combination with other agents and in treating benign prostatic hypertrophy.

\section{Drug Classes}

\section{Thiazide-type diuretics}

The majority of randomized controlled trials have used a tiazidetype diuretic in the treatment arm and there is sufficient data demonstrating their effectiveness in older patients. In ALLHAT trial, chlorthalidone arm was associated with fewer cardivascular complications than amlodipine and lisinopril. At five year follow-up, the incidence of fatal coronary heart disease and nonfatal myocardial infarction was the same for all three agents [68]. In SHEP trial, older adults with isolated systolic hypertension were assigned to chlorthalidone therapy or placebo as initial treatment. The incidence of stroke and cardiac events were lower in the treatment grup [42]. In MRC trail, elderly hypertensive patients were assigned to three groups; hyrochlorothiazide plus amloride or atenolol or placebo. Hydrochlorthiazide plus amloride group resulted in decreased incidence of stroke and all cardiovascular events [69]. Chlorthalidone has more powerful effects on blood pressure than hydrochlorothiazide at same doses. The most common adverse effects are metabolic (hypokalemia, hyperuricemia, and impaired glucose intolerance). Hyperuricemia should especially be checked during follow-up as uric acid levels may also increase as a physiological change in aging, and high levels can precipitate gout arthritis which is common at this age group. Furthermore, hyperuricemia is a predictor of cardiovascular events in hypertensive elderly. These side effects can be reduced at low doses. Combination of thiazide type diuretics with renin angiotensine system (RAS) blockers or potasium sparing diuretics helps to maintain normal potasium levels.Indapamid is a good choice of diuretic in the oldest old in the light of the results of HYVET study. It is efficient and shows less metabolic side effects, so it is safe and effective in older adults.

\section{Calcium channel blockers}

Although the two main types of CCBs have been demonstrated to treat hypertension effectively in older adults, long acting dihydropyridines such as amlodipine, nifedipine, and nitrendipine are most widely studied in trails $[47,53,68]$. CCBs are the first choice in isolated systolic hypertension together with diuretics. In the ACCOMPLISH trail, elderly patients with high cardiovascular risk, were assigned to combination therapy with benazepril plus amlodipine or hydrochlorothiazide. Combination of benazepril plus amlodipine provided a reduction in cardiovcular events, although attained blood pressure meassurements were similar in two groups. The protective effect against stroke with CCBs is demonstrated in two trails $[47,53,68]$. The most common side effect of CCBs are peripheral edema which can be attenuated by combination of RAS blockers; headache, bradycardia, and constipation. Also they have negative inotropic effect on heart; especially nondihydropiridine CCBs should be avoided in patients with heart failure, amlodipine was proved to be safe in patients with heart failure. Nondihydropiridine CCBs could be preferred in patients with atrial fibrillation who can not tolerate $\beta$ blockers, but these two classes should not be combined because they may induce heart block.

\section{Angiotensin-converting Enzyme Inhibitors (ACEI) and Angiotensin Receptor Blockers (ARB)}

These agents are alternative choices for initial therapy or preferred as second line agents, in combination with thiazide diuretics or CCBs. In ACCOMPLISH study, combination of an ACEI plus a CCB resulted in beter cardiovascular outcomes in the elderly. In HYVET trial, patients aged 80 years and older were assigned to placebo and indapamid as initial therapy, and perindopril and matched placebo was added if target blood pressure $<150 / 80 \mathrm{~mm} \mathrm{Hg}$ was not met. At two years, death from stroke and from all causes was reduced in the active treatment group. In ALLHAT trial, lisinopril had worse cardiovascular outcomes than chlorthalidone, partly due to lower attained blood pressure with chlorthalidone. Some specific indications for these agents are heart failure, prior myocardial infarction, left ventricular hypertrophy, chronic kidney disease, proteinuria, and diabetes melltus. Many elderly hypertensive patients have these indications. Chronic cough is the main side effect; angioedema is uncommon but potentially dangerous. ARBs do not cause cough, less likely to cause angioedema. Hyperkalemia and an increase in serum creatinin may occur but these side effects are reversible when dose is reduced or drug therapy is discontinued. As geriatric patients are prone to electrolyte disturbances, hyperkalemia should especially be checked during follow-ups. In patients with bilateral renal artery stenosis these agents are contraindicated, because they may worsen renal functions. ACEI and ARB combination is not recommended in older adults, because of increased adverse effects on renal functions $[15,53,68]$.

\section{Beta blockers}

$\beta$-blockers reduce heart rate and cardiac output, also decrease renin release. So they are effective in patients with high plasma renin activity such as younger patients. However, they are not the first choice for treatment of hypertension in older adults, unless there is a compeling 
indication. Antihypertensive properties of all $\beta$-blockers may be similar but pharmacologic properties and side effects are different within the class. Vasodilator $\beta$-blockers carvedilol and nebivolol, have no adverse effect on glucose and lipid metabolism. However, they are more advantageous in heart failure than in hypertension. $\beta$-blockers have some cardioprotective effects in patients with stable congestive heart failure and previous myocardial infarction. In the absence of compeling indications (heart failure, previous MI, angina pectoris, atrial fibrillation, and aortic aneurysm), $\beta$-blockers are not recommended as initial therapy $[4,60]$. They are inferior, compared to other drugs in prevention of stroke, especially atenolol [70].

\section{Conclusion}

The primary goal of treating hypertension is to reduce cardiovascular morbidity and mortality. Several randomized clinical trials in elderly patients have clearly and consistently demonstrated benefit of antihypertensive therapy in patients even as old as $>85$ years of age. "However, the patients in these trails were relatively healthy. There is limited evidence available in managing frail elderly hypertensive patients, but some studies suggest that frail older adults have beter outcomes with higher blood pressures (SBP>140 mm Hg even SBP $>160 \mathrm{~mm} \mathrm{Hg}$ ) [71-74]. Therefore, blood pressure goals should be set according to the patients' age and functional status. Limitations of current approach to hypertension in geriatric patients are due to lack of evidence especially in the oldest old and frail older people. In clinical trials the geriatric patients aged 85 years and over and frail older adults are usually excluded. Further clinical studies examining these populations are needed to achive better understanding for this special group. Geriatric patients should be monitored throughout treatment, for adverse drug events, orthostatic hypotension which may cause falls, syncope, and even death. As a general statement 'start low, go slow, but go!' should be applied for older adults. Hypertension is not normal for elderly and should be treated, but with caution and appropriate medication schedules. Beers criteria, START and STOPP criteria can be used to avoid inappropriate drug usage in geriatric patients $[75,76]$.

\section{References}

1. Stamler J, Stamler R, Neaton JD (1993) Blood pressure, systolic and diastolic, and cardiovascular risks. US population data. Arch Intern Med 153: 598-615.

2. He J, Whelton PK (1999) Elevated systolic blood pressure and risk of cardiovascular and renal disease: overview of evidence from observational epidemiologic studies and randomized controlled trials. Am Heart J 138: 211-219.

3. Lewington S, Clarke R, Qizilbash N, Peto R, Collins R (2002) Age-specific relevance of usual blood pressure to vascular mortality: a meta-analysis of individual data for one million adults in 61 prospective studies. Lancet 360: 1903-1913.

4. Mancia G, Fagard R, Narkiewicz K, Redon J, Zanchetti A, et al. (2013) 2013 ESH/ESC Guidelines for the management of arterial hypertension: the Task Force for the management of arterial hypertension of the European Society of Hypertension (ESH) and of the European Society of Cardiology (ESC). J Hypertens, 31: 1281-1357.

5. Lloyd-Jones D, Adams R, Carnethon M, De Simone G, Ferguson TB, et al. (2009) Heart disease and stroke statistics--2009 update: a report from the American Heart Association Statistics Committee and Stroke Statistics Subcommittee. Circulation 119: 480-486.

6. Altun B, Arici M, NergizoÄŸlu G, Derici U, Karatan O, et al. (2005) Prevalence, awareness, treatment and control of hypertension in Turkey (the PatenT study) in 2003. J Hypertens 23: 1817-1823.
7. Vasan RS, Beiser A, Seshadri S, Larson MG, Kannel WB, et al. (2002) Residual lifetime risk for developing hypertension in middle-aged women and men: The Framingham Heart Study. JAMA 287: 1003-1010.

8. Altun B, SÃ $1 / 4$ leymanlar G, UtaÅŸ C, ArÄ \pm nsoy T, AteÅŸ K, et al. (2012) Prevalence, awareness, treatment and control of hypertension in adults with chronic kidney disease in Turkey: results from the CREDIT study. Kidney Blood Press Res 36: 36-46.

9. Arici M, Turgan C, Altun B, Sindel S, Erbay B, et al. (2010) Hypertension incidence in Turkey (HinT): a population-based study. J Hypertens 28: 240-244.

10. Guo F, He D, Zhang W, Walton RG (2012) Trends in prevalence, awareness, management, and control of hypertension among United States adults, 1999 to 2010. J Am Coll Cardiol 60: 599-606.

11. Bromfield SG, Bowling CB, Tanner RM, Peralta CA, Odden MC, et al. (2014) Trends in hypertension prevalence, awareness, treatment, and control among US adults 80 years and older, 1988-2010. J Clin Hypertens (Greenwich) 16: 270-276.

12. Egan BM, Zhao Y, Axon RN (2010) US trends in prevalence, awareness, treatment, and control of hypertension, 1988-2008. JAMA 303: 2043-2050.

13. Halil M, Cankurtaran M, Ulger Z, Balam Yavuz B, Altun B, et al. (2006) Awareness and control of hypertension among the elderly in a university hospital. Clin Exp Hypertens 28: 683-693.

14. Staessen JA, Wang JG, Thijs L (2001) Cardiovascular protection and blood pressure reduction: a meta-analysis. Lancet 358: 1305-1315.

15. Beckett NS, Peters R, Fletcher AE, Staessen JA, Liu L, et al. (2008) Treatment of hypertension in patients 80 years of age or older. $\mathrm{N}$ Engl J Med 358: 1887-1898.

16. Kostis JB, Davis BR, Cutler J, Grimm RH Jr, Berge KG, et al. (1997) Prevention of heart failure by antihypertensive drug treatment in older persons with isolated systolic hypertension. SHEP Cooperative Research Group. JAMA 278: 212-216.

17. Blood Pressure Lowering Treatment Trialists' Collaboration1, Turnbull F, Neal B, Ninomiya T, Algert C, et al. (2008) Effects of different regimens to lower blood pressure on major cardiovascular events in older and younger adults: meta-analysis of randomised trials. BMJ 336: 1121-1123.

18. Sytkowski PA, D'Agostino RB, Belanger AJ, Kannel WB (1996) Secular trends in long-term sustained hypertension, long-term treatment, and cardiovascular mortality. The Framingham Heart Study 1950 to 1990. Circulation 93: 697-703.

19. Chobanian AV, Bakris GL, Black HR, Cushman WC, Green LA, et al. (2003) The Seventh Report of the Joint National Committee on Prevention, Detection, Evaluation, and Treatment of High Blood Pressure: the JNC 7 report. JAMA 289: 2560-2572.

20. James PA, Oparil S, Carter BL, Cushman WC, Dennison-Himmelfarb C, et al. (2014) 2014 evidence-based guideline for the management of high blood pressure in adults: report from the panel members appointed to the Eighth Joint National Committee (JNC 8). JAMA 311: 507-520.

21. Weber MA, Schiffrin EL, White WB, Mann S, Lindholm LH, (2014) Clinical practice guidelines for the management of hypertension in the community: a statement by the American Society of Hypertension and the International Society of Hypertension. J Clin Hypertens (Greenwich) 16: 14-26.

22. Mancia G, De Backer G, Dominiczak A, Cifkova R, Fagard R, et al. (2007) 2007 Guidelines for the Management of Arterial Hypertension: The Task Force for the Management of Arterial Hypertension of the European Society of Hypertension (ESH) and of the European Society of Cardiology (ESC). J Hypertens 25: 1105-1187.

23. Dao HH, Essalihi R, Bouvet C, Moreau P (2005) Evolution and modulation of age-related medial elastocalcinosis: impact on large artery stiffness and isolated systolic hypertension. Cardiovasc Res 66: 307-317.

24. Duprez DA (2006) Role of the renin-angiotensin-aldosterone system in vascular remodeling and inflammation: a clinical review. J Hypertens 24: 983-991. 
25. Burt VL, Whelton P, Roccella EJ, Brown C, Cutler JA, et al. (1995) Prevalence of hypertension in the US adult population. Results from the Third National Health and Nutrition Examination Survey, 1988-1991. Hypertension 25: 305-313.

26. Franklin SS, Gustin W 4th, Wong ND, Larson MG, Weber MA, et al. (1997) Hemodynamic patterns of age-related changes in blood pressure. The Framingham Heart Study. Circulation 96: 308-315.

27. Epstein M, Hollenberg NK (1976) Age as a determinant of renal sodium conservation in normal man. J Lab Clin Med 87: 411-417.

28. Franklin SS (1999) Ageing and hypertension: the assessment of blood pressure indices in predicting coronary heart disease. J Hypertens Suppl 17: S29-36.

29. Pinto E (2007) Blood pressure and ageing. Postgrad Med J 83: 109-114.

30. Cherubini A1, Lowenthal DT, Paran E, Mecocci P, Williams LS, et al (2007) Hypertension and cognitive function in the elderly. Am J Ther 14: 533-554.

31. Reitz C, Tang MX, Manly J, Mayeux R, Luchsinger JA (2007) Hypertension and the risk of mild cognitive impairment. Arch Neurol 64: 1734-1740.

32. Fagard RH (2002) Epidemiology of hypertension in the elderly. Am J Geriatr Cardiol 11: 23-28.

33. Ostchega Y, Dillon CF, Hughes JP, Carroll M, Yoon S (2007) Trends in hypertension prevalence, awareness, treatment, and control in older U.S adults: data from the National Health and Nutrition Examination Survey 1988 to 2004. J Am Geriatr Soc 55: 1056-1065.

34. Sander GE (2004) Hypertension in the elderly. Curr Hypertens Rep 6: 469-476.

35. Turgut F, Yesil Y, Balogun RA, Abdel-Rahman EM (2013) Hypertension in the elderly: unique challenges and management. Clin Geriatr Med 29: 593-609.

36. Franklin SS, Jacobs MJ, Wong ND, L'Italien GJ, Lapuerta P (2001) Predominance of isolated systolic hypertension among middle-aged and elderly US hypertensives: analysis based on National Health and Nutrition Examination Survey (NHANES) III. Hypertension 37: 869-874.

37. Safar H, Chahwakilian A, Boudali Y, Debray-Meignan S, Safar M, et al. (2006) Arterial stiffness, isolated systolic hypertension, and cardiovascular risk in the elderly. Am J Geriatr Cardiol 15: 178-182.

38. Kannel WB (1996) Blood pressure as a cardiovascular risk factor: prevention and treatment. JAMA 275: 1571-1576.

39. Izzo JL Jr, Levy D, Black HR (2000) Clinical Advisory Statement. Importance of systolic blood pressure in older Americans. Hypertension 35: 1021-1024.

40. Young JH, Klag MJ, Muntner P, Whyte JL, Pahor M, et al. (2002) Blood pressure and decline in kidney function: findings from the Systolic Hypertension in the Elderly Program (SHEP). J Am Soc Nephrol 13: 2776-2782.

41. Wilking SV, Belanger A, Kannel WB, D'Agostino RB, Steel K (1988) Determinants of isolated systolic hypertension. JAMA 260: 3451-3455.

42. (1991) Prevention of stroke by antihypertensive drug treatment in older persons with isolated systolic hypertension. Final results of the Systolic Hypertension in the Elderly Program (SHEP). SHEP Cooperative Research Group. JAMA 265: 3255-3264.

43. Somes GW, Pahor M, Shorr RI, Cushman WC, Applegate WB (1999) The role of diastolic blood pressure when treating isolated systolic hypertension. Arch Intern Med 159: 2004-2009.

44. Pepine CJ, Handberg EM, Cooper-DeHoff RM, Marks RG, Kowey P, et al. (2003) A calcium antagonist vs a non-calcium antagonist hypertension treatment strategy for patients with coronary artery disease. The International Verapamil-Trandolapril Study (INVEST): a randomized controlled trial. JAMA 290: 2805-2816.

45. Vokó Z, Bots ML, Hofman A, Koudstaal PJ, Witteman JC, et al. (1999) Jshaped relation between blood pressure and stroke in treated hypertensives. Hypertension 34: 1181-1185.
46. Yavuz BB, Yavuz B, Tayfur O, Cankurtaran M, Halil M, et al. (2009) White coat effect and its clinical implications in the elderly. Clin Exp Hypertens 31: 306-315.

47. Staessen JA, Fagard R, Thijs L, Celis H, Arabidze GG, et al. (1997) Randomised double-blind comparison of placebo and active treatment for older patients with isolated systolic hypertension. The Systolic Hypertension in Europe (Syst-Eur) Trial Investigators. Lancet 350: 757-764.

48. Applegate WB, Davis BR, Black HR, Smith WM, Miller ST, et al. (1991) Prevalence of postural hypotension at baseline in the Systolic Hypertension in the Elderly Program (SHEP) cohort. J Am Geriatr Soc 39: 1057-1064.

49. Rutan GH, Hermanson B, Bild DE, Kittner SJ, LaBaw F, et al. (1992) Orthostatic hypotension in older adults. The Cardiovascular Health Study. CHS Collaborative Research Group. Hypertension 19: 508-519.

50. Atli T, Keven K (2006) Orthostatic hypotension in the healthy elderly. Arch Gerontol Geriatr 43: 313-317.

51. Liu L, Wang JG, Gong L, Liu G, Staessen JA (1998) Comparison of active treatment and placebo in older Chinese patients with isolated systolic hypertension. Systolic Hypertension in China (Syst-China) Collaborative Group. J Hypertens 16: 1823-1829.

52. O'Malley K, Cox JP, O'Brien E (1991) Further learnings from the European Working Party on High Blood Pressure in the Elderly (EWPHE) study: focus on systolic hypertension. Cardiovasc Drugs Ther 4 Suppl 6: 1249-1251.

53. Jamerson K, Weber MA, Bakris GL, Dahlöf B, Pitt B, et al. (2008) Benazepril plus amlodipine or hydrochlorothiazide for hypertension in high-risk patients. N Engl J Med 359: 2417-2428.

54. Hansson L, Lindholm LH, Ekbom T, Dahlof B, Lanke J, et al. (1999) Randomised trial of old and new antihypertensive drugs in elderly patients: cardiovascular mortality and morbidity the Swedish Trial in Old Patients with Hypertension-2 study. Lancet 354: 1751-1756.

55. Wing LM, Reid CM, Ryan P, Beilin LJ, Brown MA, et al. (1997) Second Australian National Blood Pressure Study (ANBP2). Australian Comparative Outcome Trial of ACE inhibitor- and diuretic-based treatment of hypertension in the elderly. Management Committee on behalf of the High Blood Pressure Research Council of Australia. Clin Exp Hypertens 19: 779-791.

56. Forette F, Seux ML, Staessen JA, Thijs L, Babarskiene MR, et al. (2002) The prevention of dementia with antihypertensive treatment: new evidence from the Systolic Hypertension in Europe (Syst-Eur) study. Arch Intern Med 162: 2046-2052.

57. Tuomilehto J, Rastenyte D, Birkenhäger WH, Thijs L, Antikainen R, et al. (1999) Effects of calcium-channel blockade in older patients with diabetes and systolic hypertension. Systolic Hypertension in Europe Trial Investigators. N Engl J Med 340: 677-684.

58. Messerli FH, Mancia G, Conti CR, Hewkin AC, Kupfer S, et al. (2006) Dogma disputed: can aggressively lowering blood pressure in hypertensive patients with coronary artery disease be dangerous? Ann Intern Med 144: 884-893.

59. Denardo SJ, Gong Y, Nichols WW, Messerli FH, Bavry AA, et al. (2010) Blood pressure and outcomes in very old hypertensive coronary artery disease patients: an INVEST substudy. Am J Med 123: 719-726.

60. Aronow WS, Fleg JL, Pepine CJ, Artinian NT, Bakris G, et al (2011) ACCF/AHA 2011 expert consensus document on hypertension in the elderly: a report of the American College of Cardiology Foundation Task Force on Clinical Expert Consensus documents developed in collaboration with the American Academy of Neurology, American Geriatrics Society, American Society for Preventive Cardiology, American Society of Hypertension, American Society of Nephrology, Association of Black Cardiologists, and European Society of Hypertension. J Am Coll Cardiol 57: 2037-2114.

61. Appel LJ, Espeland MA, Easter L, Wilson AC, Folmar S, et al. (2001) Effects of reduced sodium intake on hypertension control in older individuals: results from the Trial of Nonpharmacologic Interventions in the Elderly (TONE). Arch Intern Med 161: 685-693. 
Citation: Gunes ARIK and Burcu Balam YAVUZ (2014) Hypertension in Older Adults-Geriatrician Point of View. J Gerontol Geriat Res 3: 1000182. doi:10.4172/2167-7182.1000182

Page 7 of 7

62. Ruixing Y, Weixiong L, Hanjun Y, Dezhai Y, Shuquan L, et al. (2008) Diet, lifestyle, and blood pressure of the middle-aged and elderly in the Guangxi Bai Ku Yao and Han populations. Am J Hypertens 21: 382-387.

63. Protogerou AD, Safar ME, Iaria P, Safar H, Le Dudal K, et al. (2007) Diastolic blood pressure and mortality in the elderly with cardiovascular disease. Hypertension 50: 172-180.

64. Odden MC, Peralta CA, Haan MN, Covinsky KE (2012) Rethinking the association of high blood pressure with mortality in elderly adults: the impact of frailty. Arch Intern Med 172: 1162-1168.

65. Rosendorff C, Black HR, Cannon CP, Gersh BJ, Gore J, et al (2007) Treatment of hypertension in the prevention and management of ischemic heart disease: a scientific statement from the American Heart Association Council for High Blood Pressure Research and the Councils on Clinical Cardiology and Epidemiology and Prevention. Circulation, 115: 2761-2788.

66. Dahlof B, Devereux RB, Kjeldsen SE, Julius S, Beevers G, et al (2002) Cardiovascular morbidity and mortality in the Losartan Intervention For Endpoint reduction in hypertension study (LIFE): a randomised trial against atenolol. Lancet 359: 995-1003.

67. Treatment to Prevent Heart Attack Trial (ALLHAT) (2003) Antihypertensive,Lipid-Lowering Treatment to Prevent Heart Attack Trial Collaborative Research, G. Diuretic versus alpha-blocker as firststep antihypertensive therapy: final results from the Antihypertensive and Lipid-Lowering Hypertension 42: 239-246.

68. ALLHAT Officers and Coordinators for the ALLHAT Collaborative Research Group The Antihypertensive and Lipid-Lowering Treatment to Prevent Heart Attack Trial. (2002) Major outcomes in high-risk hypertensive patients randomized to angiotensin-converting enzyme inhibitor or calcium channel blocker vs diuretic: The Antihypertensive and Lipid-Lowering Treatment to Prevent Heart Attack Trial (ALLHAT). JAMA 288: 2981-2997.

69. (1992) Medical Research Council trial of treatment of hypertension in older adults: principal results. MRC Working Party. BMJ 304: 405-412.

70. Messerli FH, Grossman E, Goldbourt U (1998) Are beta-blockers efficacious as first-line therapy for hypertension in the elderly? A systematic review. JAMA 279: 1903-1907.

71. Dorresteijn JA, van der Graaf Y, Spiering W, Grobbee DE, Bots ML, et al (2012) Relation between blood pressure and vascular events and mortality in patients with manifest vascular disease: J-curve revisited. Hypertension 59: 14-21.

72. Mattila K, Haavisto M, Rajala S, Heikinheimo R (1988) Blood pressure and five year survival in the very old. Br Med J (Clin Res Ed) 296: 887-889.

73. Langer RD, Ganiats TG, Barrett-Connor E (1991) Factors associated with paradoxical survival at higher blood pressures in the very old. Am J Epidemiol 134: 29-38.

74. Rastas S, Pirttilä T, Viramo P, Verkkoniemi A, Halonen P, et al. (2006) Association between blood pressure and survival over 9 years in a general population aged 85 and older. J Am Geriatr Soc 54: 912-918.

75. Gallagher P, O'Mahony D (2008) STOPP (Screening Tool of Older Persons' potentially inappropriate Prescriptions): application to acutely ill elderly patients and comparison with Beers' criteria. Age Ageing 37: 673-679.

76. Barry PJ, Gallagher P, Ryan C, O'mahony D (2007) START (screening tool to alert doctors to the right treatment)--an evidence-based screening tool to detect prescribing omissions in elderly patients. Age Ageing 36: 632-638. 